\title{
Anal fistula associated with anal fissure
}

\author{
P. $\operatorname{Garg}^{1,2} \mathbb{C}$
}

Received: 6 May 2020 / Accepted: 25 May 2020 / Published online: 31 May 2020

(c) Springer Nature Switzerland AG 2020

\section{Dear Sir,}

Anal fistula can develop from deepening of anal fissure (fissure-fistula) [1]. What proportion of "cryptoglandular fistulas' are due to fissure-fistula is not clear. Out of 294 patients operated for anal fistula at our institution from 2016 to December 2019, 34 (11.6\%) had a history of anal fissure at the site where the fistula developed. Of these 34 fissurefistula patients, $24(70.6 \%)$ had posterior midline, $8(23.5 \%)$ had anterior midline and $2(5.9 \%)$ had lateral fistulas. In the fissure-fistula group, the development of posterior fistula was significantly more common than in the non-fissure associated group $(70.6 \%$ vs $47.6 \%, p=0.01)$ while the anterior fistula was significantly less common than in the non-fissure group (the group in which there was no history of fissure symptoms) ( $23.5 \%$ vs $42.7 \%, p=0.039)$.

Interestingly, the median time taken to develop fistula after initiation of fissure was 24 months.

In our patient population it took an average of about 2 years to develop fistula from fissure. So there is adequate time available and if anal fissure is managed properly, then the progression to anal fistula can perhaps be prevented.

Further studies are needed to corroborate the findings of this study as well as to prospectively study a cohort of anal fissure patients to ascertain as what proportion of them develop anal fistula.
Acknowledgements Nil.

Author contributions PG: concept, designed study, acquisition of data, analysis of data, drafting, revising, final approval of the draft, submission of manuscript.

\section{Compliance with ethical standards}

Conflict of interest The author declares that he has no conflict of interest.

Ethical approval Approval for the study was taken from the Institute Ethics Committee.

Informed consent Informed consent was taken from all the patients.

\section{Reference}

1. Garg P, Lakhtaria P, Gupta V (2018) Oral plus local antibiotics significantly reduce the need for operative intervention in chronic anal fissure: a novel finding. Indian J Surg 80:415-420. https:// doi.org/10.1007/s12262-017-1617-z

Publisher's Note Springer Nature remains neutral with regard to jurisdictional claims in published maps and institutional affiliations.
P. Garg

drgargpankaj@yahoo.com

Indus International Hospital, Mohali, Punjab, India

2 Garg Fistula Research Institute, 1042, Sector-15, Panchkula, Haryana 134113, India 